\title{
Asante Indigenous Lost Wax Cast Evolution for Profitable Economic Growth
}

\author{
Samuel Baah Kissi ${ }^{1}$, Steve Kquofi², Peggy Ama Fening ${ }^{1}$ \\ ${ }^{1}$ Department of Industrial Art, Kwame Nkrumah University of Science and Technology, Kumasi, Ghana \\ ${ }^{2}$ Department of Educational Innovations in Science and Technology, Kwame Nkrumah University of Science and Technology, Kumasi, \\ Ghana
}

\author{
Email address: \\ kissisamuelbaah@yahoo.com (S. B. Kissi)
}

\section{To cite this article:}

Samuel Baah Kissi, Steve Kquofi, Peggy Ama Fening. Asante Indigenous Lost Wax Cast Evolution for Profitable Economic Growth. American Journal of Art and Design. Vol. 6, No. 3, 2021, pp. 95-102. doi: 10.11648/j.ajad.20210603.14

Received: March 17, 2021; Accepted: August 25, 2021; Published: September 3, 2021

\begin{abstract}
Globalization and competition with modern industrial products is the basic and fundamental setback for the viability, sustainability and preservation of local cultural heritage of traditional arts in most part of the world. This has been the case of Casting done at Krofofrom in the Asante Kingdom of Ghana. Castings done at Krofofrom can be improved to compete with the global market for profitable economic growth. This study examined the adaptation strategies in the preservation and sustainability of the Krofofrom village traditional brass casting technology. The composition of casting mould cores used by Krofofrom artisans comprises charcoal, cow dung and clay. Although this composition results in a very stable core that disintegrates easily after casting, defects in the form of pin holes are a common occurrence on the inner walls of the cast artefacts, thereby ruining the finish. In many instances these pinholes are difficult if not impossible to remove or seal. To improve the performance of the existing core, experiments were carried out to determine suitable materials and the proportions required to reformulate and enhance the core composition. The addition of Plaster of Paris (P.O.P) to the composition prevented shrinkage and fracture while the presence of saw dust provided microscopic holes in the core structure to facilitate easy core disintegration after casting. High content aluminous clay component served to improve the refractory properties of the core. The new core composition comprising charcoal, P.O.P, saw dust and aluminous clay showed an improvement over the existing Krofofrom core composition. The improved composition yielded efficient cores that disintegrated easily after casting and impart smoother inner wall surface devoid of pinholes. Piercing and carving useful for wax pattern production is achievable when the appropriate wax formulation developed in this study is adhered to.
\end{abstract}

Keywords: Metal Casting, Core Composition, Beeswax, Lost Wax Casting, Refractory Materials

\section{Introduction}

Culture is the totality of learned, socially transmitted customs, knowledge, material objects and behaviour. It includes the ideas, value, customs and artefacts of a group of people [14]. Culture is a pattern of human activities and the symbols that give these activities significance. It is what people eat, how they dress, beliefs they hold and activities they engage in. It is the totality of the way of life evolved by a people in their attempts to meet the challenges of living in their environment, which gives order and meaning to their social, political, economic, aesthetic and religious norms and modes of organization thus distinguishing people from their neighbours. However, culture can be transmitted or acquired through information or symbol. Cultural identity is those attributes, behavioural patterns, lifestyles, social structures and norms that distinguish a people from other peoples [12]. These are passed on laterally or inherited from one generation to another (cultural heritage), or horizontally passed on from one society to another through such agent as globalization. The globalization of the production and distribution of goods and services is a welcome development for many people in that it offers them access to products that they would not otherwise have. However, some are concerned that the changes brought about by globalization threaten the viability of locally made products and the people who produce them. The expansion of trade in cultural products is increasing the exposure of all societies to foreign cultures. And the exposure to foreign 
cultural goods frequently brings about changes in local cultures, values, and traditions. Although there is no consensus on the consequences of globalization on national cultures, many people believe that a people's exposure to foreign culture can undermine their own cultural identity. Numerous commentators, from across the traditional political spectrum, have argued that markets destroy culture and diversity. John Gray, an English conservative, in his book entitled False Dawn: The Delusions of Global Capitalism (2000) has argued that global free trade is ruining the world's politics, economies, and cultures. In his view, traditional and local culture in many parts of the world is being battered out of existence by the indiscriminate dumping of large quantities of slick commercial and media products, mainly from the developed world.

Lost wax casting has been practiced all over the world by various cultures since prehistoric times. The basic technique is always the same although there might be slight changes either in the core materials, mould making or in how the cast pieces are finished $[2,16]$. A recent improvement in the craft for modern industrial use is referred to as investment casting'. Casting is of crucial importance especially where mass production and accuracy of artefacts are desired to satisfy demand and supply [16].

In Ghana, gold-weights are associated with lost wax casting, just as the craft of gold smithing itself is associated with the Asante kingdom [4]. Until the change of currency in the Ashanti kingdom from gold dust to paper notes and metal coins, casting was used to produce gold-weights which served as counter-weights for weighing the gold dust used for making regalia for the Asantehene (Ashanti King) and his sub chiefs [11]. Krofofrom artisans initially made their mould cores from 3 parts charcoal and 2 parts clay. This core composition cast perfectly but did not disintegrate easily after casting thus making retrieval of cast artefacts rather cumbersome. The toughness of this Krofofrom core can be attributed to the fact that clay tends to gain strength when subjected to heat during casting. The subsequent difficulty encountered by artisans as they try to disintegrate cores after casting not only slows down production but can also precipitate the marring of precious cast works. To improve the core's performance some artisans began adding fresh cow dung to the composition presumably to aid in the disintegration of the core after casting. Although cow dung appears to perfectly bind the other components within the composition and apparently allows it to disintegrate easily, it causes the core to retain water even after de-waxing. This moisture in the core turns into vapour as it encounters the molten metal and this interaction affects the integrity of the cast artefacts. The added cow dung does not appear to impart smoother inner walls to hollow cast objects. Other artisans in a bid to improve the core's performance modify the ratio of the core composition to 3 parts charcoal and 1 part clay. When the core composed with these components was tested, it was found that it collapsed even before the molten metal solidified completely in the mould causing parts of the core to be filled with molten metal. This outcome indicated that the core lacked the strength to withstand the heat and pressure of the molten metal [3]. Another option exercised by the artisans was to completely burn out the cow dungcontaining core before introducing molten metal into the mould while a third test was to increase the amount of clay in the cow dung composition but then fire the core before covering it with wax. In both experiments the outcome was simply unacceptable. Pre-heating the cow dung composition to completely burn out the dung before pouring in the molten metal still resulted in a weakened core unable to withstand the pressure of the molten metal. The composition comprising 3 parts charcoal, 2 parts cow dung and 1 part clay when tested showed that cow dung in the composition did not only help in the disintegration of the core but provided strength and acted as a binder for the other components. However, when this composition was pre-heated to completely burn out the cow dung the core lost strength and could not withstand the pressure and temperature that the molten metal entering the mould exerted. When the clay content was increased in the composition, the core showed signs of cracks during drying and sometimes during casting and its disintegration was difficult. Also even when the core was subjected to a high temperature to completely burn out the cow dung in the composition (before the application of wax patterns), partial erosion of the core occurred during dewaxing. Core erosion again occurred during pouring of the molten metal. These core failures prompted the investigation into materials suitable for producing cores with adequate strength, ease of disintegration and pinhole-free casting.

Despite the attempts to improve quality, hollow cast objects from traditional lost wax casting have been characterized by pin holes on the inner walls.

\section{Apprenticeship}

Apprenticeship of Krofofrom bronze casting can be classified into two phases. The first phase covering the period of Nana Agyare and the second phase, the period after his death. Mr Nortey (personal communication, 4 March 2014) informed that there was virtually no apprentice to the craft at the early period when Nana Agyare was strong and could do everything himself. Owing to the nature of the work done by Nana Agyare which were always in secrecy it made it imperative to engage someone very sober and trustworthy to undergo apprenticeship training. To this end the choice of apprentice to the craft was done with strict observation and carefulness. He normally locked himself up in his workshop whenever working and only called for somebody when he needed help. Such a person was the one earmarked for an apprentice. With this in mind he always called a particular person who by so doing learnt the craft by his own intelligence. With time and observation the person started to use some of the tools and materials in modelling as and when Nana Agyare permitted whenever he was working and was never permitted to practise openly until the death of Nana Agyare. At his death there were a few boys in his family who had acquired the skills and were able to carry on the craft. At this same time also other people who had learnt the craft 
secretly started practising. Women were never allowed to practise by taboo. The craft became the work of almost every family in the village [6].

The second phase of apprenticeship came after the death of Nana Agyare. At this time any person interested in the craft was accepted into apprenticeship. However the craft did not extend outside the village and that earlier apprenticeship depend heavily on family ties. Before a person was accepted into apprenticeship the father of the would-be apprentice had to see the craftsmen and discuss things over with him. Initially a token fee was charged and a bottle of drink usually schnapps was collected. But now a reasonable amount is charged. The drink is used to pour libation and as a binder or a seal to the agreement. The libation forms part of the initiation ceremony of apprenticeship. The fee is however deferred for payment until the training is completed. The initiation continues by showing the apprentice and the guardian round the duties of the apprentice. From then onwards he starts the training of the craft. The actual training starts by the introduction of the trainee to the uses of various items in the workshop. The first stage involves watching the master during the preparation of materials such as clay and wax which do not require much skill. From this stage he moves on to colouring of the models with charcoal powder and helps in the making of moulds. Trainees take active part in the fanning during melting of metal. Gradually as he continues in the helping the master while working he acquires the skill of the craft. The training is done by both oral and practical methods. The master directs the apprentice performs other duties such as preparing and cleaning the workshop before and after work. He does odd jobs like washing and helping the master's wife in the kitchen when not needed by the master. He is fed free during working period. These odd jobs mostly by those who have just entered the training. The duration of apprenticeship depends on the trainee's ability to learn fast. There is however a time limit specified in the agreement ranging from one to three years. After the training he may decide to leave and set up his own workshop or be employed by the master [6].

Graduation of the apprentice is done in a very simple manner. Again libation is poured by the master who calls on the gods for safety, protection and flourishing of the craft, to enable the graduant and himself prosper in life. After the fee charged for the training had been settled fully, the apprentice is free to leave the master's workshop. It is interesting to note that the craft is now being taught in the continuation class of the elementary school at the village [1].

\section{Materials and Methods}

To prevent pinholes and enhance core disintegration, there was the need to evaluate the materials being used by Krofofrom artisans for mould, core and wax pattern preparation: bee's wax, charcoal, cow dung and clay. The new composition formulated to improve the core consist of charcoal, clay, saw dust and Plaster of Paris (P.O.P) which replaces the cow dung in the original composition. The selection of the materials for the research did not pose much of a challenge since clay in ancient times was used as investment material and later the introduction of gypsum which is now known as Plaster of Paris as binder in most investments for casting [15]. The method used for the study was the Lost Wax Casting. Plaster of Paris did not go through any preparation process since its grain particle was already fine. Beeswax was used for making wax pattern. Other additives were added to the bees wax to improve its workability and to hold various wax modelling techniques which have not been used by the local artisans. Qualitative research design was used, descriptive and experimental research techniques were employed in gathering data.

\section{Experimental Procedures}

\subsection{The Core Composition of Traditional Metalsmith}

Clay, charcoal and fresh cow dung are the three materials prepared and used by the traditional artisans for the production of cores. Beeswax is used for producing wax patterns. The wax is drawn out either in wire or sheet form. Beeswax usually contained sand particles due to improper handling by beeswax collectors [10]. Two methods used in purifying bees wax from dirt was to skim the lump of wax with the aid of a sharp knife and the second method was to melt the wax over a heat source until it was completely melted. It was then poured through an 80 mesh sieve into a bowl full of cold water. The wax on cooling and hardening was kneaded for use.

The charcoal was pounded in a metal mortar with wooden pestle into powder. It was sieved through 120 microns to obtain fine grains. Clay was also prepared in the same vein and reduced into slip. Cow dung was generally collected from the rear bers. The composition comprises 3 parts charcoal, 2 parts cow dung and 1 part clay. Charcoal helps in providing porosity to the core and prevents shrinkage. Fresh cow dung was used because of the fresh fibre which leaves microscopic pores in the core after casting and aids in its easy disintegration. Cow dung helps in proper binding of all the constituent materials, facilitates the drying of the core. Clay in the composition strengthens and hardens the core when fired. The addition of cow dung although serves the purpose of binding other components within the composition perfectly, yet retains water in the core even after de-waxing. This moisture in the core turns into vapour which is trapped during casting and manifest as pin holes on the inner walls of the cast item. The core retained its former "green" or natural characteristics of being sticky and pliable when wet even after casting. It was revealed that cow dung even when pulverized still contains some amount of moisture. The study also showed that the amount of heat used in de-waxing and the pre-pouring state was not able to completely burn out cow dung. Cow dung core surfaces when in contact with the hot molten metal (e.g. brass) undergoes further combustion and the cow dung releases carbon dioxide, water vapour and ashes. "Micro blow holes" on the surface of the inner walls 
of the cast item which manifest themselves as pinholes are probably caused by this water vapour released from the combustion of cow dung.

\subsection{Improving the Core Composition}

In improving the traditional core composition, the study replaced cow dung with P.O.P and sawdust. The study made a composition of clay, charcoal powder, sawdust and P.O.P with varied proportions. Clay was used as a binder and a refractory in the composition in order to withstand heat without fracture. In this regard clay with high alumina content such as Kenyasi Adwumem was used [17]. Its properties include plasticity, shrinkage, fineness of grain, colour after firing, hardness, cohesion and capacity of the surface to take decoration. Clay often forms colloidal suspensions when immersed in water and becomes hard and lose its plasticity when subjected to heat. Burning wood less of oxygen produces charcoal. Charcoal in the composition helps in the burning of the core and minimizes shrinkage. Sawdust as fine as 80 mesh was also used for the study. Sawdust provides microscopic holes in the core which facilitates disintegration of the core after casting. Plaster of Paris (P.O.P) is prepared from gypsum (calcium sulphate dehydrate). Plaster of Paris in the core composition helps in drying of the core, prevents shrinkage and provides strength to withstand fracture. Saw dust was obtained from saw mills within Krofofrom and clay also from Kenyase a suburb of Kumasi in the Ashanti region all without a cost except charcoal and P.O.P which were bought. It was observed that a bag of P.O.P when obtained could be used for a number of works since its percentage in the core composition is not that great and another observation made was that the first coat and the core after coming into contact with the high temperature of the molten metal during casting, burns and they can serve as charcoal for subsequent casting.

Table 1. Component weights of core samples 1 to 4.

\begin{tabular}{|c|c|c|c|c|}
\hline SAMPLE & CHARCOAL & P.O.P & SAWDUST & CLAY \\
\hline KCS1 & $293.7 \mathrm{~g} / 3$ parts & $78.5 \mathrm{~g} / 1$ part & $18 \mathrm{~g} / 1 / 2$ parts & $52.4 \mathrm{~g} / 1 / 2$ parts \\
\hline $\mathrm{KCS} 2$ & $391.6 \mathrm{~g} / 4$ parts & $39.3 \mathrm{~g} / 1 / 2$ parts & $18 \mathrm{~g} / 1 / 2$ parts & $26.2 \mathrm{~g} / 1 / 4$ part \\
\hline $\mathrm{KCS} 3$ & $293.7 \mathrm{~g} / 3$ parts & $78.5 \mathrm{~g} / 1$ part & $18 \mathrm{~g} / 1 / 2$ parts & $104.7 \mathrm{~g} / 1$ part \\
\hline $\mathrm{KCS} 4$ & $293.7 \mathrm{~g} / 3$ parts & $39.3 \mathrm{~g} / 1 / 2$ parts & $18 \mathrm{~g} / 1 / 2$ parts & $52.4 \mathrm{~g} / 1 / 2$ parts \\
\hline
\end{tabular}

\section{Results}

The casting result was undesirable (figure 2- figure 5). The cores got burnt and parts of the core filled with metal. All the sample cast objects had this deformity. This can probably be due to the cores not being able to withstand the pressure and high temperature of the molten metal as it solidified. When one considered the properties of the materials used for the sample cores, it would be observed that when clay, charcoal, sawdust and P.O.P are subjected to high temperature they with the exception of clay, lose strength and break down into ashes. Clay when subjected to high temperature loses plasticity but becomes very hard [17]. A review of all the core samples, shows that although they disintegrated easily after casting and created smooth inner walls, yet they could not withstand the high temperature of brass during solidification. The core was very light, lacked strength and could not withstand the high temperature and pressure of molten brass as the molten brass solidified upon casting.

There was the need to improve the strength of the cores. Further core development was done and labelled 1CPSC3, 2CPSC4 and CPSC5. These new samples were developed from the previous core samples experimented upon. Sample 1CPSC3 was an improvement of samples KCS1 and KCS3. Sample 2CPSC4 was an improvement of samples KCS2 and KCS4. Table 2 below shows details of the sample composition. Biscuit size samples were made and tested for shrinkage, disintegration and strength just as was done with the first samples. After these tests, three similar wax patterns in weight, size and embellishment as those used for the previous experiment were also injected (Figure 1) with the new core compositions and labelled 1CPSC $3,2 \mathrm{CPSC} 4$, and
CPSC5. The samples were later cast in brass and the results were quite encouraging. After these successful sample castings, other models were made from each of the successfully tested cores. The results of these subsequent sample castings were satisfactory.

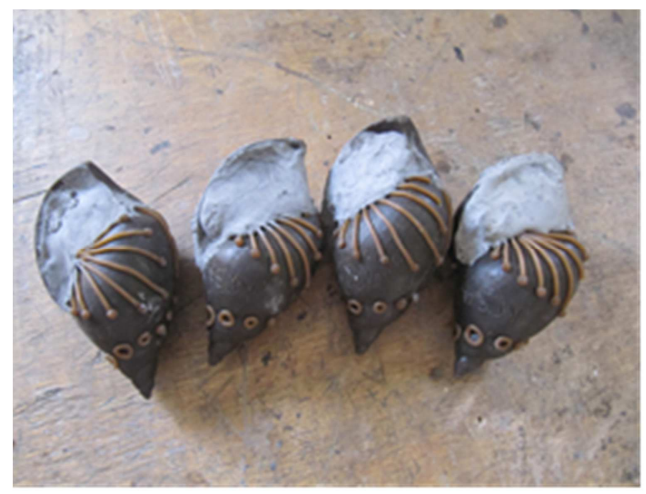

Figure 1. Core injected test samples.

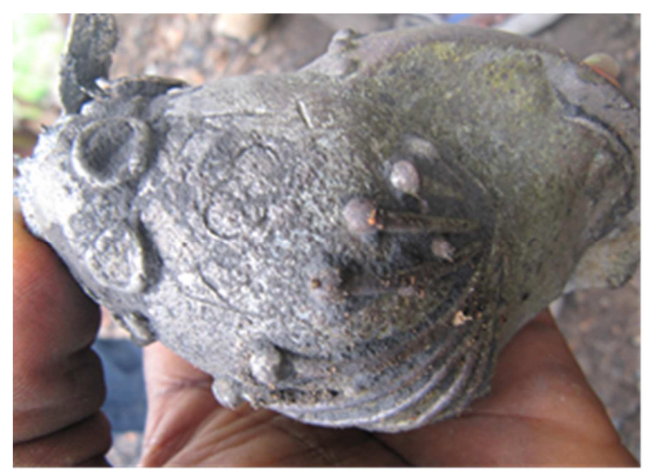

Figure 2. Sample KCS1 after casting. 


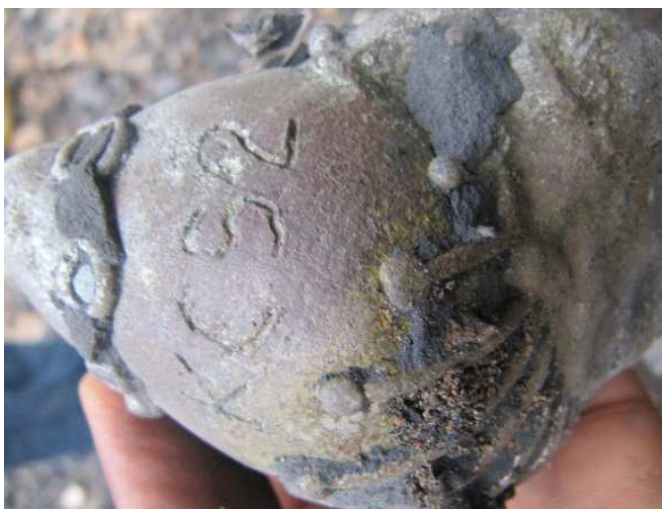

Figure 3. Sample KCS2 after casting.

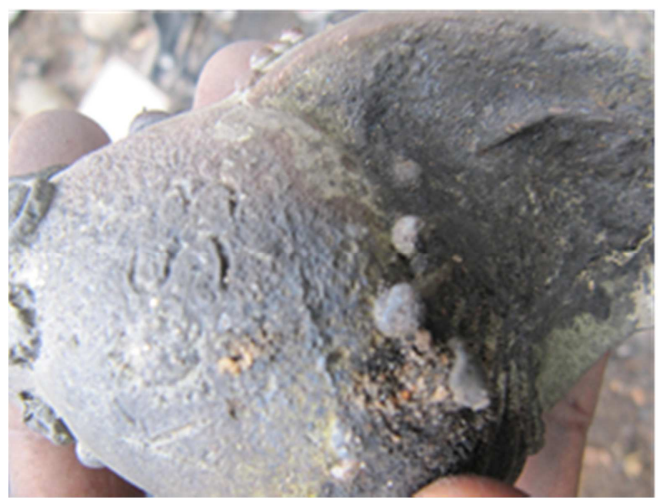

Figure 4. Sample KCS3 after casting.

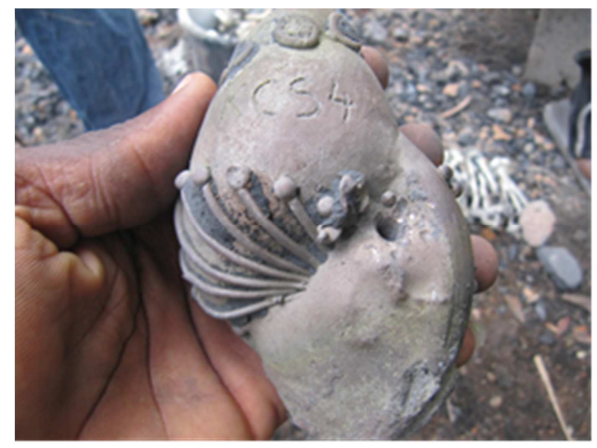

Figure 5. Sample KCS4 after casting.

\subsection{Fabrication of Samples}

Four samples of varied proportions were made from Charcoal, Plaster of Paris, Saw Dust and Clay. The four samples were labelled according to the beginning alphabet of the materials hence CPSC 1-3. The materials were weighed in $1500 \mathrm{~g}$ batches based on the recipes presented in Table 2 . The materials were dried and mixed in a plastic bowl and water was added to an even constituency. In order to break the lumps and trapped air pockets, the hand was used in kneading the constituent. Sample cores were made in flat biscuit shapes which were then weighed. A measurement of $25 \mathrm{~mm}$ was marked on the four recipes. They were dried and then heated to the melting point of brass to test for shrinkage and ability to withstand heat (Figure 9).

Table 2. Component weights of 'Improved' core samples.

\begin{tabular}{lllll}
\hline SAMPLE & CHARCOAL & P.O.P & SAWDUST & CLAY \\
\hline 1CPSC3 & $293.7 \mathrm{~g} / 3$ parts & $78.5 \mathrm{~g} / 1$ part & $18 \mathrm{~g} / 1 / 2 \mathrm{part}$ & $314.1 \mathrm{~g} / 3$ parts \\
2CPSC 4 & $342.7 \mathrm{~g} / 31 / 2 \mathrm{parts}$ & $39.3 \mathrm{~g} / 1 / 2 \mathrm{parts}$ & $18 \mathrm{~g} / 1 / 2 \mathrm{parts}$ & $314.1 \mathrm{~g} / 3 \mathrm{parts}$ \\
CPSC5 & $293.7 \mathrm{~g} / 3$ parts & $39.3 \mathrm{~g} / 1 / 2 \mathrm{parts}$ & $35.9 \mathrm{~g} / 1 \mathrm{part}$ & $261.8 \mathrm{~g} / 21 / 2 \mathrm{parts}$ \\
\hline
\end{tabular}

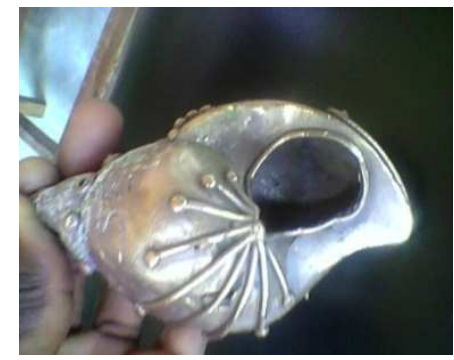

Figure 6. Sample KCS5 after casting.

The first four compositions labelled KCS1, KCS2, KCS3 and KCS4, (Table 1) were all a failure. Parts of the cores collapsed in the mould. This was possibly due to the fact that the composition of all four cores had less clay and thus could not probably have the strength to support the high temperature and pressure of molten brass during the pouring and solidification stage. Another experiment was conducted using the same core materials as in the previous four: charcoal, clay, P.O.P and sawdust but this time in different proportions other than those used for the four experimental cores. The second experiments were an improvement on the earlier experiments. The second experimental samples labelled 1CPSC3, 2CPSC4 and CPSC5 were a success (Figure 6 - Figure 8).

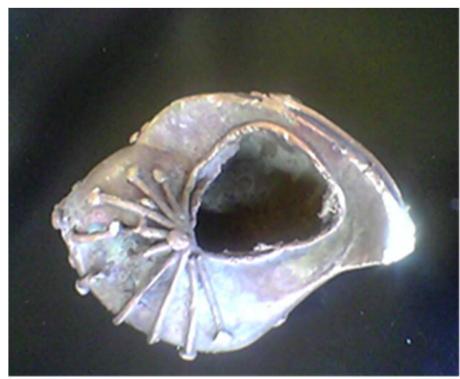

Figure 7. Sample 2 KCS4 after casting.

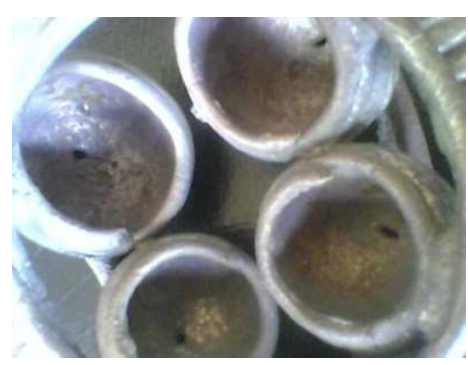

Figure 8. Sample 1KCS3 after casting. 


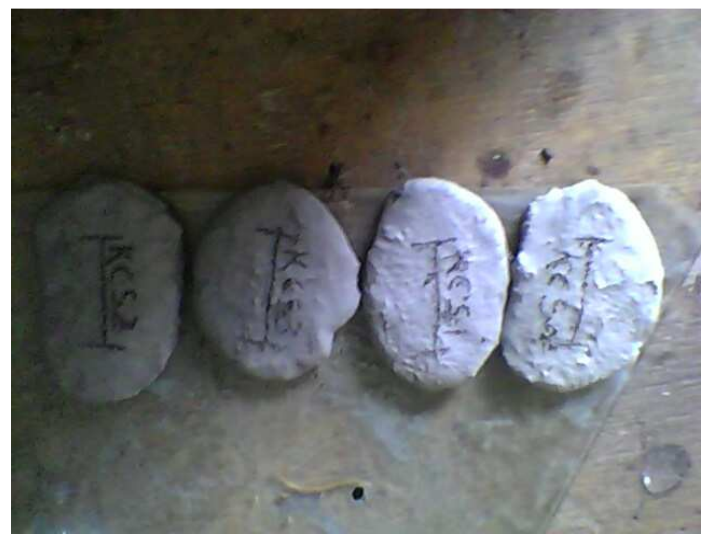

Figure 9. Shrinkage test.

\subsection{Wax Experiment}

Various experiments were conducted to produce a variety of waxes from a combination of beeswax, paraffin, candle wax and kerosene to help improve Asante casting being practised today. Aluminium container and spoon were used because wax does not wet and stick to aluminium surface. Digital scale was used to weigh the molten waxes in grams. The wax mixture samples were labelled as group $\mathrm{C}(\mathrm{C} 1, \mathrm{C} 2$, $\mathrm{C} 3$, and $\mathrm{C} 4)$, comprising beeswax and candle. Group P (P1, $\mathrm{P} 2, \mathrm{P} 3$, and $\mathrm{P} 4)$, comprised mixtures of beeswax and paraffin wax, while group $\mathrm{K}$ consisted of beeswax and kerosene. The last group CP1 consisted of mixtures of beeswax, candle and paraffin wax. Details of these experiments are as follows:

Table 3. Wax compositions and physical characteristics.

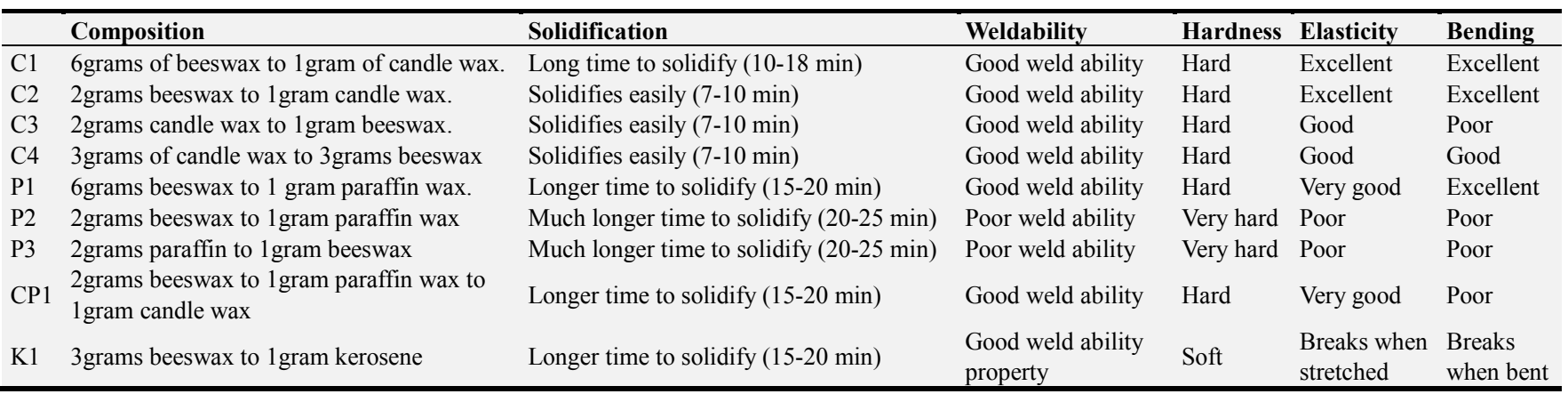

The two main beeswaxes that are marketed are yellow beeswax and white beeswax. White beeswax is obtained by bleaching yellow beeswax with hydrogen peroxide, sulphuric acid or sunlight. Beeswax primarily consists of five component groups of a mixture of esters of fatty acids and fatty alcohols, paraffinic hydrocarbons, and free fatty acids; minor amount of fatty alcohols are also present. These five groups amplified below are: free fatty acids (typically 12-14\%), most of which are saturated $(\mathrm{Ca} .85 \%)$ and have a chain length of C24-C32. Secondly, free primary fatty alcohols (Ca. 1\%) with a chain length of C28-C35. Thirdly, linear wax monoesters and hydroxyl monoesters (35-45\%) with chain lengths generally of C40-C48. The esters are derived almost exclusively from palmitic acid, 15-hydroxypalmitic acid, and Oleic acid. Fourthly, complex wax esters (15-27\%) containing 15hydroxypalmitic acid which through their hydroxyl group are linked to another fatty-acid molecule. In addition to such diesters, tri- and higher esters are also found. Lastly, oddnumbered straight chain hydrocarbons (12-16\%) with a predominant chain length of $\mathrm{C} 27-\mathrm{C} 33$. The composition of beeswax is said to depend to some extent, on the subspecies of the bees, the age of the wax, and the climatic circumstances of its production. However, the variation in composition occurs mainly in the relative amounts of the different components present, rather than in their chemical identity $[5,7]$.

Various additives were mixed with beeswax in order to formulate different mixtures suitable for various kinds of designs as well as help give the wax compositions certain desirable properties (see Table 3 for details) to facilitate wax working under various ambient temperatures. A composition that contains paraffin wax took much longer time to solidify when compared to either candle compositions or just beeswax. Candle wax solidifies faster than beeswax and therefore it is advisable to mix candle wax into beeswax and not beeswax into candle wax. Candle wax when molten is colourless and does not give out any smoke until it is introduced to excess heat which in most cases produces smoke. Paraffin when introduced to excess heat makes cracking noise and produces smoke. Beeswax when introduced to excess heat makes a cracking noise and sometimes catches fire. Molten beeswax produces a sweet smell and turns chocolate or brown colour when introduced to excess heat: discolouration occurs when beeswax is introduced to heat above 80-85 degrees Celsius.

\section{Results and Conclusions}

Cores used for lost wax casting by metalsmiths at Krofofrom have gone through several transformations even prior to this research work which aims primarily at improving the casting of hollow objects. In the 1700`s, metalsmiths of the Asante Kingdom were using a core whose composition was 3 parts charcoal powder (120 mesh) and 2 parts clay mixed with water to a consistency suitable for core modelling. This core composition is currently used by Asantehene's metalsmiths at Ensuasi in Kumasi [13]. Although this core casts very perfectly and gives fine inner walls to cast objects, it does not disintegrate easily after casting and tends to result in distorted and warped castings.

In this era of mass production as practised in Krofofrom, the 
metalsmith cannot afford to lose valuable cast objects through distortion and difficulty in core removal. The introduction of fresh cow dung to the composition of charcoal and clay was to improve upon the disintegration of the core after casting. Fresh cow dung is the undigested plant part that has passed through the animal`s alimentary canal. The fibre in the dung provides microscopic holes in the core which allows heat retention and improves the disintegration of core after casting. Although cow dung appears to help in the disintegration of core after casting, it nonetheless creates pinholes in the inner walls of cast hollow objects. According to Kumar and Shende, effective combustion of cow dung takes place when the dung is pulverized [9]. When cow dung is completely burnt its byproducts are carbon dioxide, water vapour and ashes. Their research substantiates the point that the amount of heat that the core with the unpulverised dung is subjected to during dewaxing is not able to get the dung completely burnt. An experiment was conducted by this researcher whereby a core after routine de-waxing was immersed in water. The wet core retained its former "green" or natural characteristics of being sticky and pliable. Such cow dung core surfaces when in contact with the hot molten metal (e.g. brass) undergoes further combustion and the cow dung releases carbon dioxide, water vapour and ashes. "Micro blow holes" on the surface of the inner walls of the cast item which manifest themselves as pinholes are probably caused by this water vapour released from the combustion of cow dung.

The core composition of the 1700's ( 3 part charcoal and 2 part clay) was altered to a ratio of 3 parts charcoal to 1 part clay. When this core composition was tested, it was found that it collapsed even before the molten metal solidified completely causing parts of the core to be filled with molten metal. This indicated that the composition lacked the strength to withstand the heat and pressure of the molten metal. One idea was to completely burn out the core before introducing molten metal into the mould. Another was to increase the amount of clay in the cow dung composition and then burn the core before covering it with wax. In both instances the outcome was unacceptable. Pre-heating the cow dung composition to completely burn the dung before introducing molten metal resulted in a weakened core unable to withstand the pressure of the molten metal.

The composition comprising 3 parts charcoal, 2 parts fresh cow dung and 1 part clay when tested showed that cow dung in the composition did not only help in the disintegration of the core but provided strength and acted as a binder for the other components. However, when this composition was preheated to completely burn out the cow dung the core lost strength and could not withstand the pressure and temperature that the molten metal entering the mould exerted. When the clay content was increased in the composition, the core showed signs of cracks during drying and sometimes during casting. Also when the core was subjected to a high temperature in order to completely burn out the cow dung in the composition before wax patterns were applied, it was discovered that erosion of parts of the core had occurred during de-waxing. Core erosion again occurred during pouring of the molten metal. The need to try different materials for producing cores that would have adequate strength, easy disintegration and pinhole-free casting became obvious.

The first four compositions were all a failure. Parts of the cores collapsed in the mould. This was possibly due to the fact that the composition of all four cores had less clay and thus could not probably have the strength to support the high temperature and pressure of molten brass during the pouring and solidification stage. Another experiment was conducted using the same core materials as in the previous four: charcoal, clay, P.O.P and sawdust but this time in different proportions other than those used for the four experimental cores. The second experiments were an improvement on the earlier experiments.

Without the application of P.O.P and saw dust in the production of the core material, inner walls of cast hollow objects made at Krofofrom will still be characterised by pinholes. Piercing and carving useful for wax pattern production is achievable when the appropriate wax formulation developed in this study is adhered to. High content aluminous clay component served to improve the refractory properties of the core. The new core composition comprising charcoal, P.O.P, saw dust and aluminous clay showed an improvement over the existing Krofofrom core composition. The improved composition yielded efficient cores that disintegrated easily after casting and impart smoother inner wall surface devoid of pinholes.

\section{References}

[1] Asiedu, A. B., Labi, K. A. and Osei-Tutu, B., 2009. An Asanteman-World Bank Heritage Development Initiative in Promoting Partnership with Ghanaian Traditional Leaders. Africa Today, 55 (4), pp. 3-26.

[2] Apley, A. (2009). African lost Wax Casting: The Tada figure, Retrieved from www.metmuseum.org on 26th of April, 2010.

[3] Collins, N. (2007). Cow dung in Lost Wax Casting. Retrieved from www.lost-wax-casting.com on 23rd of February, 2011.

[4] Garrard, F. T. (1980), Akan weights and the Gold trade. New York and London: Longman group Ltd, p. 209.

[5] Gupta P. R. B. (1983), Foundry Engineering. India, Tech India Publication, pp. 19 and 154 to 157.

[6] Gyekye, K. (1996). African Cultural Values An Introduction. Sankofa Publishing Company. Accra.

[7] Kallenberg, L. (1981), Modeling in Wax for Jewellery and Sculpture. New York: Chilton Book Company.

[8] Kissi, S. B. (2011), Evaluation of Bees Wax and Core Materials for Traditional Lost Wax Casting. M. F. A Thesis, KNUST: Kumasi.

[9] Kumar and Shende (2006). Cooking Stove. Madhav Institute of Technology and Science. www.appropedia.org/efficientcooking. On 5th July, 2010. 
[10] Leclarcq, B. (2008). The Honeybee and Man. Retrieved from http://google-search.com on the 11th of August, 2009.

[11] Martha, E. (1989), Early Akan Gold. London, African Arts, Cambridge: Cambridge African Studies Centre, Vol. 22, p. 87.

[12] Omekwu, C. O. (2006). African culture and libraries: The Information Technology Challenges. Electronic Library, 24 (2), 247-248.

[13] Ross, D. H. (1977), The Iconography of Ashanti Sword Ornament. California: African Art, African Studies Center. University of California. Vol 6, p. 18.
[14] Schaefer, R. T. (2002). Sociology: A brief introduction. 4th ed. Boston: McGraw Hill.

[15] Sias R. F. (2005), Lost-Wax Casting Old, New and Inexpensive Method. South Carolina, Woodsmere Press, Pendleton.

[16] Waters, L. (1993), Lost Wax Casting in Ashanti, Kumasi, University Press, KNUST. p. 34.

[17] Worral, W. E. A. (1986) Clay and Ceramic Raw Materials, New York: Elsevier Applied Science. p. 14. 